\title{
Comparative Study between Effect of Clomiphene Citrate, Tamoxifen and Letrozole on Endometrial Thickness in Induction of Ovulation in Patient with Polycystic Ovarian Syndrome
}

\author{
Abd El Monaem Mohamed Zakaria', Mohamed Elsayed Hammour ${ }^{1}$, Mekky Abd El Monaem Aly², \\ Ahmed Hussein Abd El Hamed Holla ${ }^{1}$ \\ ${ }^{1}$ Obstetrics \& Gynecology Department, Faculty of Medicine, Al-Azhar University \\ ${ }^{2}$ Clinical Pathology Department, Faculty of Medicine, Al-Azhar University \\ Corresponding Author: Ahmed Hussein Abd El Hamed Holla, E-mail: ahmedhussein89@outlook.com, Phone: 01005252333
}

\begin{abstract}
Background: Infertility is the inability of a married couple to conceive within one year in spite of regular marital life. Globally $10-15 \%$ of the married couples are experiencing this problem. CC is non-steroidal selective estrogen receptor modulator (SERM), has both estrogen agonist and antagonist properties. It binds to estrogen receptors primarily in the hypothalamus, which interrupts the negative feedback of the increasing estrogen level and results in continued production of FSH, which stimulates follicular growth and maturation. Its anti-estrogenic effect causes long standing estrogen receptor depletion due to its long half life ( 2 weeks), so it has adverse effects on the quality and quantity of cervical mucus and negative impact on endometrial development causing its thinning, implantation failure and decreased blood flow during the peri-implantation stage.

Objectives: The aim of the study is to compare the effect of the following 3 drugs during induction of ovulation: 1- Clomiphene citrate, 2- Tamoxifen, 3- Letrozole.

Patients and Methods: This study was carried out in El Entag El Harby Hospital. The patients were recruited from the Infertility outpatient clinic between December 2017 and June 2018. This prospective study included 150 infertile women who were diagnosed as anovulatory infertility and meet the inclusion criteria. This study followed the ethical committee rules of Obstetrics \& Gynecology department, Al Azhar University. For all women with anovulatory infertility in this study; explanation of the study procedures was done to all women sharing in the study and informed written consents were obtained. In the current study, patients were divided into three groups, each group formed of 50 patients: Group 1 (CC), Group 2 (letrozole), Group 3 (TMX). First of all, the groups in our study were matched as regard to age, BMI, type and duration of infertility.

Results: The current study shows a statistically significant difference between the three groups regarding the endometrial thickness, which was significantly thinner in group 1 (CC) than the other two groups; group 2 (letrozole) and group 3.

Conclusion: Clomiphene citrate has a negative effect on endometrial thickness which is mostly attributed to its antiestrogenic effect. A triple layered endometrium (trilaminar pattern) is associated with higher pregnancy rates; therefore, patients receiving $\mathrm{CC}$ with non trilaminar pattern have reduced pregnancy rates.
\end{abstract}

Keywords: Clomiphene Citrate, Tamoxifen, Letrozole, Endometrial Thickness, Polycystic Ovarian Syndrome.

\section{INTRODUCTION}

Infertility is the inability of a married couple to conceive within one year in spite of regular marital life. Globally $10-15 \%$ of the married couples are experiencing this problem ${ }^{(\mathbf{1})}$.

Anovulation accounts for about $20-25 \%$ of causes of infertility as ovulation is a core event for reproduction. Anovulation may be due to problems affecting the ovary, pituitary or hypothalamus. These causes have been organized by the world health organization (WHO) into three main categories based on the site of the lesion and as reflected by gonadotropin production: WHO type 1 (hypogonadotropic hypogonadism): caused by any lesion affecting pituitary or hypothalamus and affecting gonadotropin production, WHO type 2 (normogonadotropic hypogonadism): the commonest cause of anovulation and is most commonly caused by polycystic ovarian syndrome (PCO), WHO type 3 (hypergonadotropic hypogonadism): usually is an indication of ovarian failure ${ }^{(\mathbf{1})}$.

Polycystic Ovarian Syndrome (PCO) is the most common endocrinal disorder in women of reproductive age and is the primary cause of anovulatory infertility. Its prevalence range from 6$10 \%$ in general population. Its diagnostic criteria at least two of the following (Rotterdam criteria): 1) Oligo or anovulation, 2) Hyperandrogenism (laboratory confirm or by clinical symptoms), 3) Polycystic ovaries on ultrasound ${ }^{(2)}$.

Ovulation induction involves the use of medication to stimulate development of one or more mature follicles in the ovaries of women who have anovulation and infertility. These women don't regularly develop mature follicles without help from ovulation enhancing drugs as Selective 
Estrogen Receptor Modulator (clomiphene citrate and tamoxifen), Aromatase Inhibitors (letrozole), Gonadotropins, etc. Treatment with these drugs has the potential to result in pregnancy if the woman has good quality eggs in her ovaries and if other causes of infertility are absent ${ }^{(\mathbf{1}}$.

$\mathrm{CC}$ is non-steroidal selective estrogen receptor modulator (SERM), has both estrogen agonist and antagonist properties. It binds to estrogen receptors primarily in the hypothalamus, which interrupts the negative feedback of the increasing estrogen level and results in continued production of FSH, which stimulates follicular growth and maturation ${ }^{(3)}$.

\section{AIM OF THE WORK}

The aim of the study is to compare the effect of the following 3 drugs during induction of ovulation: 1- Clomiphene citrate, 2- Tamoxifen, 3Letrozole.

\section{PATIENT AND METHODS}

\section{Study Population and Design:}

Setting: The study was carried out in El Entag El Harby Hospital. The patients were recruited from the outpatient infertility clinic between December 2017 and June 2018.

Sample size calculation: The required sample size has been calculated using the $\mathrm{G}^{*}$ Power@ software version 3.1.0 (Institut für Experimentelle Psychologie, Heinrich Heine Universität, Düsseldorf, Germany).

Study design: This prospective study included 150 infertile women who were diagnosed as anovulatory infertility and meet the inclusion criteria. This study followed the ethical committee rules of obstetrics and gynecology department, $\mathrm{Al}$ Azhar University. For all women with anovulatory infertility in this study; explanation of the study procedures is done to all women sharing in the study and informed written consents were obtained.

Inclusion Criteria for Patients in the Study: Age: 18 - 35 years. Body mass index (BMI): $18-30 \quad \mathrm{~kg} / \mathrm{m}_{2}$. Patients with normogonadotropic hypogonadism (WHO type 2). Normal uterus and patent fallopian tubes proved by hystrosalpingography (HSG). Normal semen analysis of the husband. Normal serum Prolactin. Women with documented anovulation by measuring progesterone on day 21 or by performing ultrasound during ovulation phase.

Exclusion Criteria for Patients in the Study: Hyperprolactinemia, thyroid dysfunction, active liver diseases, etc. Local diseases as endometriosis, ovarian tumors, hydro- or pyosalpinx etc. Patients with previous history of ovarian drilling. All patients were divided by computer allocation method into 3 groups, each group formed of 50 patients.

Group A: This group included 50 patients who were under ovulation induction with clomiphene citrate. Patients took $100 \mathrm{mg}$ of the drug daily for 5 days, starting from day 3 to day 7 of the cycle. Each tablet of the drug is $50 \mathrm{mg}$, so patients took the dose in form of 2 tablets all together after breakfast for one cycle.

Group B: This group included 50 patients who were under ovulation induction with letrozole. Patients took $5 \mathrm{mg}$ of the drug daily for 5 days, starting from day 3 to day 7 of the cycle. Each tablet of the drug is $2.5 \mathrm{mg}$, so patients took the dose in form of 2 tablets all together after breakfast for one cycle.

Group C: This group included 50 patients who were under ovulation induction with tamoxifen. Patients took $60 \mathrm{mg}$ of the drug daily for 5 days, starting from day 3 to day 7 of the cycle. Each tablet of the drug is $20 \mathrm{mg}$, so patients took the dose in form of 3 tablets all together after breakfast for one cycle. All patients were subjected to the following: history, physical examination, investigations, resistance index (RI): pulsatility index (PI), pulsatility index (PI), Primary outcome.

\section{RESULTS}

Table (1): Patients' characteristics in the three study groups.

\begin{tabular}{|c|c|c|c|c|c|}
\hline \multirow[t]{2}{*}{ Variable } & $\begin{array}{c}\text { Clomiphene } \\
(\mathrm{N}=50)\end{array}$ & $\begin{array}{c}\text { Letrozole } \\
(\mathrm{N}=50)\end{array}$ & $\begin{array}{c}\text { Tamoxifen } \\
(\mathrm{N}=50)\end{array}$ & \multirow{2}{*}{$F_{(d f=2,156)}$} & \multirow{2}{*}{$\begin{array}{c}\text { p- } \\
\text { value }\end{array}$} \\
\hline & Mean \pm SD & Mean \pm SD & Mean \pm SD & & \\
\hline Age (yr) & $27.5 \pm 4.1$ & $27.2 \pm 3.9$ & $27.5 \pm 4.1$ & 0.076 & 0.927 \\
\hline $\begin{array}{l}\text { BMI } \\
\left(\mathrm{kg} / \mathrm{m}^{2}\right)\end{array}$ & $26.9 \pm 1.7$ & $26.8 \pm 1.7$ & $26.7 \pm 1.5$ & 0.185 & 0.832 \\
\hline
\end{tabular}

Non significant $\mathrm{P}>0.05$

Table (1) shows that there was no statistically significant difference in the patients' characteristics (age and BMI) between the three studied groups, $\mathrm{P}$ value $>0.05$. 
Table (2): Rate of ovulation and follicle diameter in the three study groups.

\begin{tabular}{|l|c|c|c|c|c|c|}
\hline \multicolumn{1}{|c|}{ Variable } & $\begin{array}{c}\text { Clomiphene } \\
(\mathbf{n = 5 0})\end{array}$ & $\begin{array}{c}\text { Letrozole } \\
(\mathbf{n = 5 0})\end{array}$ & $\begin{array}{c}\text { Tamoxifen } \\
(\mathbf{n = 5 0 )}\end{array}$ & $\boldsymbol{X}^{2}$ & Df & p-value \\
\hline Ovulation & $\mathrm{N}(\%)$ & $\mathrm{N}(\%)$ & $\mathrm{N}(\%)$ & & & \\
$\begin{array}{l}\text { Not } \\
\text { ovulated }\end{array}$ & $17(41.6 \%)$ & $14(28.8 \%)$ & $16(37 \%)$ & 26.7 & 2 & $<\mathbf{0 . 0 0 1}$ \\
Ovulated & $33(58.3 \%)$ & $36(71.1 \%)$ & $34(63 \%)$ & & & \\
\hline $\begin{array}{l}\text { Follicle } \\
\text { diameter }\end{array}$ & & & & & \\
$<18 \mathrm{~mm}$ & $17(41.6 \%)$ & $14(28.8 \%)$ & $16(37 \%)$ & 26.7 & 2 & $<\mathbf{0 . 0 0 1}$ \\
$\geq 18 \mathrm{~mm}$ & $33(58.3 \%)$ & $36(71.1 \%)$ & $34(63 \%)$ & & & \\
\hline
\end{tabular}

$\mathrm{X}^{2}=$ Chi square test Non significant $\mathrm{P}>0.05$

Table (2) shows that there was no statistically significant difference as regards Ovulation and follicle diameter in the three studied groups, $\mathrm{P}>0.05$.

Table (3): Endometrial thickness and Doppler indices of endometrial vessels (spiral artery) in the three study groups.

\begin{tabular}{|l|c|c|c|c|c|}
\hline \multirow{2}{*}{\multicolumn{1}{|c|}{ Variable }} & $\begin{array}{c}\text { Clomiphene } \\
(\mathbf{N}=\mathbf{5 0})\end{array}$ & $\begin{array}{c}\text { Letrozole } \\
(\mathbf{N}=50)\end{array}$ & $\begin{array}{c}\text { Tamoxifen } \\
(\mathbf{N}=50)\end{array}$ & \multirow{2}{*}{$\boldsymbol{F}_{(d f=2,156)}$} & \multirow{2}{*}{ p-value } \\
\cline { 2 - 4 } & Mean \pm SD & Mean \pm SD & Mean \pm SD & & \\
\hline $\begin{array}{l}\text { Endometrial } \\
\text { thickness (mm) }\end{array}$ & $6.9^{*} \pm 1.2$ & $9.6 \pm 1.6$ & $9.8 \pm 1.7$ & 56.720 & $<\mathbf{0 . 0 0 1}$ \\
\hline Endometrial PI & $1.67^{*} \pm 0.21$ & $1.39 \pm 0.16$ & $1.41 \pm 0.14$ & 40.791 & $<\mathbf{0 . 0 0 1}$ \\
\hline Endometrial RI & $0.72^{*} \pm 0.03$ & $0.63 \pm 0.03$ & $0.62 \pm 0.03$ & 157.010 & $<\mathbf{0 . 0 0 1}$ \\
\hline
\end{tabular}

$* \mathrm{P}<0.001$ vs. Letrozole \& Tamoxifen groups. Highly significant

Table (3) shows that there was highly statistically significant difference as regards endometrial thickness and Doppler indices (PI and RI) as measured by trans-vaginal U/S in the three studied groups, $\mathrm{P}<0.001$.

Table (4): Correlation between endometrial thickness and endometrial PI and RI

\begin{tabular}{|c|c|c|c|c|c|}
\hline & & \multicolumn{2}{|c|}{ Endometrial PI } & \multicolumn{2}{|c|}{ Endometrial RI } \\
\hline & & \begin{tabular}{|c|}
$\begin{array}{c}\text { Correlation } \\
\text { coefficient } \\
(\mathbf{r})\end{array}$ \\
\end{tabular} & p-value & \begin{tabular}{|c|}
$\begin{array}{c}\text { Correlation } \\
\text { coefficient } \\
(\mathbf{r})\end{array}$ \\
\end{tabular} & p-value \\
\hline \multirow{4}{*}{$\begin{array}{l}\text { Endometrial } \\
\text { Thickness } \\
(\mathbf{m m})\end{array}$} & $\begin{array}{l}\text { All study } \\
\text { population }(n=150)\end{array}$ & -0.850 & $<0.0001$ & -0.837 & $<0.0001$ \\
\hline & $\begin{array}{l}\text { Clomiphene } \\
\text { group }(n=50)\end{array}$ & -0.695 & $<0.0001$ & -0.58 & $<0.0001$ \\
\hline & $\begin{array}{l}\text { Letrozole group } \\
(\mathbf{n}=50)\end{array}$ & -0.776 & $<0.0001$ & -0.716 & $<0.0001$ \\
\hline & $\begin{array}{l}\text { Tamoxifen group } \\
(\mathbf{n}=50)\end{array}$ & -0.927 & $<0.0001$ & -0.818 & $<0.0001$ \\
\hline
\end{tabular}

Table (7) shows highly significant negative correlation coefficient between endometrial thickness and Doppler indices (PI and RI) in the three studied groups. So, the relation is inversely proportional, as endometrial thickness increases, the Doppler indices (PI and RI) decreases and vice versa.

\section{DISCUSSION}

First of all, the groups in our study were matched as regard to age, BMI, type and duration of infertility.

The current study shows a statistically significant difference between the three groups regarding the endometrial thickness, which was significantly thinner in group 1 (CC) than the other two groups; group 2 (letrozole) and group 3.

Our results are in agreement with Pant et al. ${ }^{(4)}$, this trial include 200 anovulatory patients, divided into 2 groups (CC and TMX). The results were ovulation rate $(65 \%$ and $63 \%$ respectively), pregnancy rate $(13.6 \%$ and $17.4 \%$ respectively), these results shows no significant difference between the two groups. Endometrial thickness shows signficant difference, which is thicker in TMX group $>8 \mathrm{~mm}$ and $\mathrm{CC}<8 \mathrm{~mm}$.

Also agree with, Hussain et al. ${ }^{(5)}$, this study included 150 anovulatory patients, divided into two groups ( $\mathrm{CC}$ and letrozole). The results were number of follicles were higher in $\mathrm{CC}$ than letrozole, ovulation rate was significantly higher in letrozole group $78.7 \%$ than CC group $53.3 \%$, pregnancy rate was higher in letrozole group $25.3 \%$ than CC group $16 \%$, mean endometrial thickness was higher in letrozole group $9.2 \mathrm{~mm}$ than $\mathrm{CC}$ group $8.4 \mathrm{~mm}$.

Another study, Roy et al. ${ }^{(6)}$, this study include 204 anovulatory patients divided into two groups (CC and letrozole). The results were number of follicles were higher in $\mathrm{CC}$ group than letrozole group, ovulation rate was almost of no difference in CC group $67.9 \%$ and letrozole group $66.6 \%$, pregnancy rate was significantly higher in letrozole group $43.8 \%$ than CC $26.4 \%$, mean endometrial thickness was significantly higher in letrozole group $9.1 \mathrm{~mm}$ than CC group $6.3 \mathrm{~mm}$.

Also, Selim and Borg ${ }^{(7)}$, this study included 200 anovulatory PCOS patients, divided into two groups (CC and letrozole). The results were ovulation rate which was slightly higher in letrozole group $70.6 \%$ than CC group $64.6 \%$, pregnancy rate was slightly higher in letrozole group $28.4 \%$ than CC group $20.2 \%$, mean endometrial thickness was higher in letrozole group $9.9 \mathrm{~mm}$ than CC group $7.7 \mathrm{~mm}$, mean endometrial blood flow (PI and RI) was significantly lower in letrozole group $(1.27,0.75)$ than $\mathrm{CC}$ group (1.67, 0.87).

Also, Badawy and Gibreal ${ }^{(8)}$, this study include 371 anovulatory PCOS patients, divided into two groups (CC and TMX). The results were the number of stimulated follicles were significantly higher in CC group than TMX, endometrial thickness was (CC 9.3mm and TMX $10.2 \mathrm{~mm}$ ), ovulation rate CC 64\% and TMX 51.6\%, Pregnancy rate CC $18.7 \%$ and TMX $10.8 \%$. 
On the other hand, our results disagree with, Kar et al. ${ }^{(9)}$, this study included 103 anovulatory patients, divided into two groups (CC and letrozole). The results were number of follicles were higher in CC group (multi-follicular) than letrozole group (monofollicular), ovulation rate was higher in letrozole group $73.08 \%$ than CC group $60.78 \%$, pregnancy rate was significantly higher in letrozole group $21.56 \%$ than CC group $8 \%$, mean endometrial thickness was almost the same between the two groups (letrozole $7.65 \mathrm{~mm}$ and CC 7.61mm).

Also, disagree with, Badawy et al. ${ }^{(\mathbf{1 0})}$, this study include 438 anovulatory PCOS patients, divided into two groups ( $\mathrm{CC}$ and letrozole). The results were total number of follicles were significantly higher in CC than letrozole group, ovulation rate was higher in $\mathrm{CC}$ group $70.9 \%$ than letrozole group $67.5 \%$, pregnancy rate was higher in CC group $17.9 \%$ than letrozole group $15.1 \%$, endometrial thickness was also higher in $\mathrm{CC}$ group 8.5- $10 \mathrm{~mm}$ than letrozole group 8- $8.2 \mathrm{~mm}$.

Also, agree with, Selim and Borg ${ }^{(7)}$, the mean endometrial blood flow (PI and RI) was significantly lower in letrozole $(1.27,0.75)$ than CC (1.67, 0.87).

And Baruah et al. ${ }^{(11)}$, this study included 50 anovulatory patients, divided into two groups (CC and letrozole). the results were number of follicles were higher in $\mathrm{CC}$ group than letrozole group, mean endometrial thickness was thicker in letrozole group $6.9 \mathrm{~mm}$ than $\mathrm{CC}$ group $5.9 \mathrm{~mm}$, mean spiral artery RI and PI, letrozole and CC groups, the mean RI of spiral artery were 0.63 and 0.79 respectively, and the mean PI of spiral artery were 1.21 and 1.55 respectively. Both RI and PI in the letrozole group showed significant lower impedance compared to CC group. Pregnancy rate was $19 \%$ with letrozole and $12.5 \%$ with CC group. The effect of letrozole showed a significantly better endometrial response compared to $\mathrm{CC}$.

The current study shows higher ovulation rate in group (2) than the other two groups, but these results are not statistically significant.

The current study shows higher Pregnancy rate in group (2) than the other two groups, but these results were not statistically significant.

Our results disagree with, Badawy and Gibreal ${ }^{(8)}$, CC $18.7 \%$ and TMX 10.8\%, and Badawy et al. ${ }^{(10)}$, letrozole $15.1 \%$ and CC $17.9 \%$.
The current study shows a statistically significant difference between the three groups regarding the number of mature follicles. In group (1), the total number of mature follicles was higher than the other two groups (2 and 3). Group (1) has tendency to multi-follicular stimulation, while Groups ( 2 and 3 ) have tendency to mono-follicular stimulation. The follicular diameter wasn't significantly different between the three groups.

Finally, our study shows characteristic thicker endometrium and lower impedance (PI and RI) with letrozole and TMX therapy than $\mathrm{CC}$, but ovulation rate and pregnancy rate shows no significant difference between any of the groups. Pant et al. ${ }^{(4)}$, Hussain et al. (5), Selim and Borg ${ }^{(7)}$ and Dhaliwal et al. ${ }^{(12)}$, studies support our study, as it show results close to our results, and this consolidates our study.

\section{CONCLUSION}

Clomiphene citrate has a negative effect on endometrial thickness which is mostly attributed to its antiestrogenic effect. A triple layered endometrium (trilaminar pattern) is associated with higher pregnancy rates; therefore, patients receiving $\mathrm{CC}$ with non trilaminar pattern have reduced pregnancy rates. Thin endometrium (less than $7 \mathrm{~mm}$ ) is usually associated with failure of implantation. Uterine artery PI less than 3 is needed to have a successful implantation. Uterine artery RI less than 0.76 is needed to have a good prediction of implantation. Ovarian artery PI less than 0.9 is needed to have a successful implantation. Ovarian artery RI less than 0.54 is needed to have a good prediction of implantation.

\section{REFERENCES}

1. Propst AM and Bates GW (2013): Evaluation and treatment of anovulatory and unexplained infertility. Obstet Gynecol Clin N Am., 39:507-519.

2. Metwally $M$ and Ledger WL (2010): Review in induction of ovulation. Obstet Gynecol Reprod Med., 21(2):47-51.

3. Seyedoshohadaei F, Zandvakily F, Shahgeibi S (2012): Comparison of the effectiveness of clomiphene citrate, tamoxifen and letrozole in ovulation induction in infertility due to isolated unovulation. Iran $\mathbf{J}$ Reprod Med., 10: 531-536.

4. Pant PR (2013): Comparison of efficacy of tamoxifen and clomiphene citrate for induction of ovulation. Medica Innovatica., 2: 68-71. 
5. Hussain NHN, Ismail M, Zain MM (2013): Randomized controlled trial of letrozole versus clomiphene citrate for induction of ovulation in women with polycystic ovary syndrome. OJOG., 3: 11-7.

6. Roy KK, Baruah J, Singla S et al. (2012): Efficacy of clomiphene citrate or letrozole in ovulation induction in women with polycystic ovarian syndrome. J Hum Reprod., 5: 20-25.

7. Selim MF and Borg TF (2012): Clomiphene citrate and Letrozole effect on endometrial and sub-endometrial vascularity in women with polycystic ovary syndrome. J Gynecol Surgery., 28: 405-410.

8. Badawy A and Gibreal A (2012): Clomiphene citrate versus tamoxifen for ovulation induction in women with polycystic ovarian syndrome. Eur J Obstet Gynecol Reprod Biol., 159;151-154.

9. Kar S (2012): Clomiphene citrate or letrozole as first line ovulation induction drug in infertile polycystic ovary syndrome women. J Hum Reprod., 5: 262-265.
10. Badawy A, Abdel Aal I, Abulatta M (2009): Clomiphene citrate or Letrozole in women with polycystic ovarian syndrome: A prospective randomized trial. Fertil Steril., 92: 849.

11. Baruah J, Roy KK, Rahman SM et al. (2009): Endometrial effects of letrozole and clomiphene citrate in women with PCOS using spiral artery Doppler. Arch Gynecol Obstet., 279: 311

12. Dhaliwal LK, Suri V, Gupta KR et al. (2011): Tamoxifen an alternative to clomiphene in women with polycystic ovary syndrome. J Hum Reprod., 4: 76-79. 